\title{
Desempenho gramatical de crianças com desenvolvimento normal e com Distúrbio Específico de Linguagem
}

\author{
Karina de Araujo ${ }^{1}$
}

Araujo K. Desempenho gramatical de crianças com desenvolvimento normal e com distúrbio específico de linguagem [tese]. São Paulo: Faculdade de Filosofia, Letras e Ciências Humanas da Universidade de São Paulo; 2007. 322f.

O Distúrbio Específico de Linguagem é uma desordem de comunicação, que tem início na infância e caracteriza-se pelo atraso na aquisição e desenvolvimento da linguagem. O objetivo desta Tese é caracterizar o desempenho gramatical de crianças normais e com Distúrbio Específico de Linguagem a partir de uma amostra de fala espontânea. Participaram desse estudo 70 crianças, com idade entre 3.1 e 6.11 anos, residentes no município de São Paulo. Os participantes foram divididos em dois grupos: GC (grupo controle) composto por 35 crianças com desenvolvimento normal de linguagem e GP (grupo pesquisa) composto por 35 crianças com diagnóstico de Distúrbio Específico de Linguagem. Esta Tese foi dividida em três estudos. Os resultados do Estudo 1 indicaram que os grupos se diferenciaram quanto ao uso dos morfemas gramaticais e quanto aos valores de extensão média do enunciado em morfemas e em palavras. No Estudo 2, os resultados indicaram que os grupos se diferenciaram em todas as faixas etárias quando analisamos os substantivos. Verificou-se diferença nas demais classes de palavras na faixa etária de 5-6 anos. No Estudo 3 verificamos que os grupos apresentam diferenças significativas quando analisamos a morfologia verbal. Concluímos que os sujeitos do GP apresentaram desempenho muito inferior aos sujeitos do GC, principalmente na faixa etária de 5-6 anos, caracterizando um déficit morfossintático que confirma a marca clínica da patologia.

Trabalho realizado no Laboratório de Investigação Fonoaudiológica em Desenvolvimento da Linguagem e suas Alterações do Departamento de Fisioterapia, Fonoaudiologia e Terapia Ocupacional da Universidade de São Paulo - USP - São Paulo (SP), Brasil, sob orientação da Profa. Dra. Debora Maria Befi-Lopes.

(1) Doutora em Semiótica e Lingüística Geral pela Faculdade de Filosofia, Letras e Ciências Humanas da Universidade de São Paulo - USP - São Paulo (SP), Brasil; Colaboradora do Laboratório de Investigação Fonoaudiológica em Desenvolvimento da Linguagem e suas Alterações do Departamento de Fisioterapia, Fonoaudiologia e Terapia Ocupacional da Universidade de São Paulo - USP - São Paulo (SP), Brasil.

Endereço para correspondência: Karina de Araujo. R. Francisca Biriba, 549/73, Santa Terezinha, São Paulo - SP, CEP 02451-040. E-mail: karaujo@usp.br 